\title{
The cognitive structuring of national identity: individual differences in identifying as American
}

\author{
SHAWN ROSENBERG* (D) and PETER BEATTIE** (D) \\ *University of California, Political Science and Psychology, Irvine, CA 92697, \\ USA \\ **The Chinese University of Hong Kong, Faculty of Social Science, Shatin, N.T. \\ Hong Kong
}

\begin{abstract}
How citizens view the nation and identify with it is an important element of the phenomenon of nationalism. While shaped by culture, this identification is also subjectively constructed by individuals. Most research on the psychology of national identity is oriented by the assumption that all people think in basically the same way, in terms of simple categories. We complement this approach by examining differences in the quality of people's thinking. While many people think in the simple concrete categorical terms assumed in most research, we argue that some individuals either do not think categorically or they think about categories in a reflective, abstract way. Consequently, these other people construct their national identity differently. To test this, we conducted an online survey that included interactive problem-solving tasks to assess cognitive functioning and standard survey items to measure the quality and affect of participants' American identity. Our results indicate significant differences in the qualities of individuals' thinking that are reflected in differences in their national identification.
\end{abstract}

KEYWORDS: Civic Nationalism, Ethnic Nationalism, Nationhood/National Identity, Political cognition, Political attitudes

Questions of national identity are at the centre of current political debates both in North America and Europe. To contribute to a broader understanding of nationalism, we draw on a novel political psychological approach and examine the different ways people identify with the nation. As the battleground issues of immigration, globalization and free trade in the 2016 American presidential elections make clear, defining a national identity and considering its policy implications are pivotal in American politics. While we focus on the American case, it is our view that the dynamics of national identity we explore are also manifest in the Brexit campaign in the UK, the rise of the AfD in Germany and the National Front in France. Throughout, concerns with who 'we' are and how we should deal with 'them' have played 
a central role in national politics. Most recent experimental and survey research on national identity adopts the social psychological approach of social identity theory (e.g. Hogg and Abrams 1988; Turner et al. 1994). While recognizing the value of this work, we adopt a different approach, one that focuses on the formal structural qualities of thinking and how they differ across persons. In our research, we examine how these differences impact the cognitive quality and affective strength of people's identification with the nation.

Social identity theory is oriented by the epistemological assumption that all people reason in basically the same way: they think in terms of categories. Typically, these categories are defined by the concrete, particular characteristics shared by members of the group. Thus, it is assumed that Americans conceptualize themselves as a categorical group, one that is defined by a set of shared distinguishing characteristics (e.g. customary practices, shared beliefs, common origins, etc.). Identifying oneself as an American suggests one does or should display these characteristics and thus contributes to one's self-definition. Cognitive balance theories (e.g. Festinger 1957; Heider 1958) and particularly the work of Henri Tajfel (1981) further suggest that this categorical conception of a social group extends to how it is valued. There is a tendency to judge the group and its various attributes, its members, customs and collective actions, in the same positive or negative manner. For the individual, their group membership impacts their selfevaluation (and vice versa). Thus, identifying as American engenders a more positive valuation of America and Americans and, by implication, of oneself.

Whereas thinking is viewed as inherently categorical, the specific categories people construct, their relative salience and their substantive content are assumed to vary across individuals. In this context, there is attention to individual differences in the relative strength of national self-identification (e.g. Huddy and Khatib 2007), its specific content, either ethnocentric or civil (e.g. Citrin et al. 2001; Schildkraut 2014) and its affective and evaluative consequences for attitudes toward country, foreign policy and ethnic minorities (e.g. De Figueiredo and Elkins 2003; Kosterman and Feshback 1989; Schatz et al. 1999). These differences are in turn explained by the learning that results from long term socialization (e.g. Citrin and Sears 2014; Schwartz et al. 2012) or short-term exposure to particular socio-political contexts (e.g. effect of a threat, Sniderman et al. 2004).

We supplement this work by hypothesizing that people not only differ in their specific definition and affective attachments to their nationality, but also in how they are able to think about the nation, and that these differences in cognition may impact the nature of their national identity. We thus challenge the orienting assumption of other work that all people reason in the same basic, categorical way. In so doing, we draw on developmental approaches in sociology (e.g. Habermas 1981/4), psychology (Kohlberg, 1981; Kegan 1994; Vygotsky 1962; Inhelder and Piaget 1958) and especially political psychology 
(e.g. Rosenberg 2002). Adopting this political psychological approach, we recognize that the social representations that constitute a political culture powerfully shape what people believe and value. However, we suggest that people do not simply internalize these dominant cultural messages. The different ways people think will affect to which messages they attend and the sense they make of them.

Some political and cultural narratives clearly dominate in a given political environment and will be adopted by nearly everyone. However, the quality of a person's thinking is an important mediating influence. As they internalise dominant information or narratives, people reconstruct what is being communicated to them in terms they can understand. Insofar as people think in qualitatively different ways, they will understand the same message's meaning and implications very differently. For example, in Rosenberg's (2002) interviews, all the participants made clear that they were aware of the equal but different powers institutionalised in the 'checks and balances' of American government. For participants who were thinking systematically, this complex arrangement was readily comprehensible, and policymaking was discussed accordingly. However, for participants who thought in a linear manner, power relations were understood in terms of simple, military-style hierarchies. When discussing policymaking, they reconstructed the complexity of American governance in their simple hierarchical terms. This led to claims that policy was decided by the President who then instructed a subordinate Congress what to do or, alternatively, that the Congress decided and the President acted as a mere spokesman.

Here, we extend this structural developmental approach to the study of national identity. In so doing, we consider differences in the quality of individuals' thinking and examine the implication of these cognitive differences for how they identify with and value being American. Like much of the research on national identity, we suggest that most people think in concrete, categorical terms and construct their national identity accordingly. However, we argue that a significant number of people do not think in this way. Some think in terms of the here and now of the flow of events, and do not readily think in terms of broader categories. Others think more complexly. They think in terms of systems of relationships, and their concerns tend to be more abstract. We hypothesize that these two groups will identify quite differently than the first, and this will have implications for the attachments they form and the evaluations they make. To test these hypotheses, we use an online survey that includes two experimental tasks to assess the quality of people's thinking, and a number of standard survey items to measure two dimensions of their American identity: their self-categorization as American and their attachment to and evaluation of America. Recognizing that level of educational attainment is often used in public opinion research as a surrogate for cognitive capacity, we also examine the relationship between type of thinking and level of educational attainment and the relative effect of each on national identification. 


\section{Forms of thinking and types of national identification}

Building on 1988 work on the development of political cognition, we focus on three types of thinking: sequential, linear and systematic. Although we will treat them here as types, they are understood theoretically as steps in a developmental progression (see also Kohlberg, 1981; Kegan 1994; Inhelder and Piaget 1958; Vygotsky 1962). Sequential thinking, the most primitive form of political cognition, develops first and is followed by linear and then systematic thinking. While it is assumed that all people have the inherent capacity to develop fully and think systematically, it is also recognized that their social circumstances may vary in ways that foster or inhibit that development. More complex and engaging social environments present greater cognitive challenges and encourage more of the exploration and reflection that fosters higher levels of cognitive development. Simpler and more constraining environments offer fewer challenges and opportunities for learning and thus tend to inhibit development. Consequently, depending on their circumstances, individuals may reach different stages of development, and therefore, as adults, their thinking will be structured in very different ways. Although any adult's views are shaped by the culture to which they are exposed, the cultural definitions and values that adults learn will always be subjectively reconstructed in terms they can understand. Therefore, even when confronted with similar events or messages, individuals who think differently will construct qualitatively different understandings of their political environment.

Here, we go beyond Rosenberg's work in two important ways. First, we extend the substantive focus to the analysis of how people think about their American national identity. We argue that the different types of thinking are more or less likely to produce the simple categorical thinking that underpins ethno-cultural definitions of nationality, and strong and affectively loaded national identifications. Second, we introduce an alternative methodology for exploring the structure of reasoning and its effects. The earlier work relied primarily on in-depth face-to-face interviews with small numbers of people. While this enabled a very accurate assessment of the quality of the inferences and definitions people make, it severely limited the number of people studied and the ease of replication. To overcome these limitations, we utilize a combination of problem-solving tasks and close-ended survey questions to examine a large population online. The types of thinking and the kind of national identification they produce are described below. (For a complete description of the types of thinking, see Rosenberg 2002, Chapters 3-5.)

\section{Sequential thinking: Relatively insignificant (or inconstant) national identification}

Sequential thinking is the first to develop and is probably most common among functionally illiterate populations. (In the US, it is estimated that between 15 and 21 per cent of adults are functionally illiterate.) It focuses on 
current and immediate events. These are understood by learning how one follows another in a particular sequence. The resulting understanding is synthetic and tied to the particulars of experience. Viewed in these terms, people are not conceived as categorical entities that are distinguished by their characteristic features. Instead people are recognized by their appearance and understood in terms of their place or participation in a specific sequence of events. Similarly, the self is not taken as a categorical object of consideration (a categorical 'me'), but rather operates as an 'acting I' that focuses on its participation in currently unfolding events. Sequential thinking also does not lead to the construction of social categories in which a group of individuals (or the self) is defined by their membership and thus their shared attributes (e.g., characteristic behaviours or beliefs, common origin, appearance). Lacking a concept of self as an object of definition and a categorical definition of social groups, people who think sequentially tend not to be concerned with self-identification or their social identity. National identity will therefore not be personally meaningful or salient. (The use of national identity labels in particular contexts may be learned if this is reinforced appropriately.)

Sequential evaluation consists of the feelings evoked during the experience of a sequence of events and their learned association with that sequence. Feelings may be associated with the particular people involved, but those people are not evaluated in a global, context-independent way. With attention turned outward the particulars of one's situation, the self is not an object of categorical evaluation. Social groups are also not objects of categorical evaluation. Therefore group or national loyalties are less likely to emerge, and the behaviours or attributes that define a national group are not valued. (This is not to say that loyalties may not emerge. When there is appropriate social reinforcement, a national label or behaviour may be associated with specific rewards and feelings and thereby acquire value. However, this learning will be evoked only in specific contexts, have few generalizable effects and is readily unlearned.)

\section{Linear thinking: Simple categorical and value-laden national identity}

Linear thinking is the next to develop and probably the most common among American adults. It abstracts specific actors and actions from the event sequences in which they are embedded. Conceived independently of a specific context, a number of these concrete objects may be considered simultaneously. This is done by using one action or actor as a conceptual anchor and then linking it to others that are observed to lead to, follow from or look like it. This leads to the construction of both (1) 'concrete' categories in which several actions or actors are connected to the same anchor and (2) linear causal relationships in which actions that follow one another are reciprocally connected as cause and effect. When a person (including the self) is the conceptual anchor, that person is defined categorically in terms of the set of the specific things she does or has done to her. When an action or attribute is 
used as the anchor, persons who perform that action or share the concrete attribute may be grouped together into a single social category. Typical anchors used to construct social categories include particular behaviours, expressed beliefs, origins (parentage or lineage), future trajectory, location (territory) or physical appearance. Identified by the concrete attributes they share, group members (including the self) are regarded as the same. The resulting social identifications tend to be depersonalizing and naturally lead to stereotyping. Constructed in this way, social identities are significant not only defining in others, but also in defining one's self. In this context, a person's national identity may be significant and will consist of the concrete characteristics (behaviours, beliefs, origins, location and appearance) that all nationals are assumed (or ought) to share.

Linear evaluation focuses on individual actors (including the self) and social groups. They are evaluated by how they are linked causally or categorically to already valued actions, actors or groups. Thus actors (including the self or a social group) may be judged (1) by the value of the effect their action produces, (2) by the degree to which their action conforms to a relevant norm of specific behaviour, or (3) by the value of the categorical group to which they belong. In a way captured by cognitive consistency theories, established evaluations tend to be self-sustaining and generalizing. On the one hand, the evaluation of a particular action tends to colour the overall evaluation of the person or the group under consideration. On the other hand, the prior evaluation of a person or group tends to colour the subsequent evaluation of their specific actions and attributes (in the case of a group, this extends to its members). As a result, national self-identification tends to be affectively charged. As one tends to value oneself, one values the groups, including the national group, with which one is associated. Reciprocally, the value of one's group applies to oneself as a member. At the same time, evaluation will tend to be consistent, so that the various attributes (or members) of a valued group will be valued in the same way. The overall result is a tendency toward 'blind patriotism.'

\section{Systematic thinking: The subjectively mediated and limited significance of national identity}

In systematic thinking, the concretely anchored causal and categorical relationships of linear thought are reconstructed as reciprocally anchored relationships, as interactions. These are understood not only by recognizing their concrete content, but also by juxtaposing them relative to one another in a system of relationships. Operating in this way, systematic thinking tends to be integrative and self-consciously interpretative. In this light, individual people or communities are regarded as self-organizing systems. When individuals are the focus, they are conceptualized as agent-subjects who have personalities or ways of thinking that actively coordinate the various claims they make, the values they espouse and the interactions they have with other people. The 
meaning of their actions, beliefs, or group memberships is thus subjectively constructed. People define, rather than are defined by, their actions or social identities. When communities are the focus, they are understood in terms of their organizational structure and culture that integrate and regulate the variety of social interactions and shared understandings that emerge within its boundaries. In this context, what individuals think and do is understood to be socially orchestrated. They are defined and differentiated from one another by the particular roles they play and the functions they serve in the social system. Constructed in this context, national identification may be significant, but unlike in linear thinking, a person's national identity is understood to be subjectively constructed (and thus its meaning will vary across persons) and partial (a national identity is one of many simultaneously operative identities that combine to define who a person is). As citizens of a polity, individuals are recognized to have varying social locations and functions such that, although they share a common abstract citizenship, they are likely to be concretely quite different from one another.

Systematic evaluation is functional. Objects are judged with reference to their impact on the integrity or coherence of the system in question. If the concern is a person (oneself or another individual), that person's characteristic interactions, orienting beliefs, social relationships and group memberships are evaluated with regard to their impact (functional or dysfunctional) on the well-being (the coherence and maintenance) of that person's self-system. Thus, a person's (or one's own) national identity may be valued. However, because it is only one of many factors contributing to personal well-being, the tendency will be to give it less value than is typical of linear thinking. When the concern is the community, the focus is on social rules or norms of behaviour, cultural beliefs or values and the institutionalized relationships between persons or groups. These various aspects of the social life of the group are evaluated in terms of how they contribute to (or detract from) the coherence of the group's culture or the coordination of its organization. As such, systematic thinking tends to value the integrity of groups and thus is likely to engender a positive evaluation of the nation, while eschewing the blind traditionalism and unquestioning loyalty more typical of linear thinking.

Tables 1 and 2 below summarize the description of the three types of thinking. The tables facilitate a comparison of types across the component dimensions of national identification.

Hypotheses

1. Individual differences in quality of thinking:

H1 Individuals will perform the problem-solving tasks in one of three different ways: sequential, linear and systematic.

2. Impact of types of thinking on the categorical quality of national identity: Sequential thinking is particularistic and embedded. It is less likely to construct the self, social groups or the nation as categorical objects. Linear 


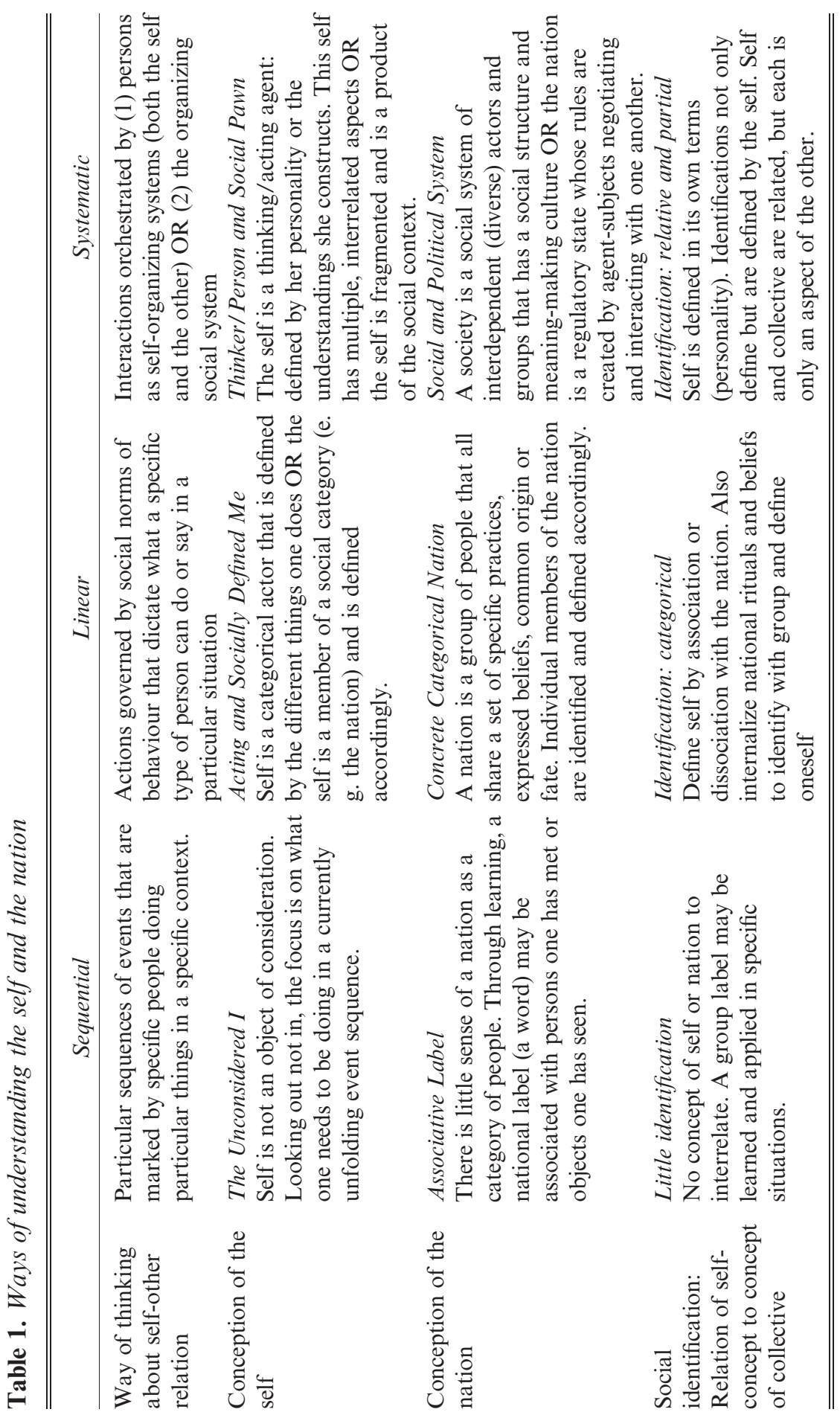




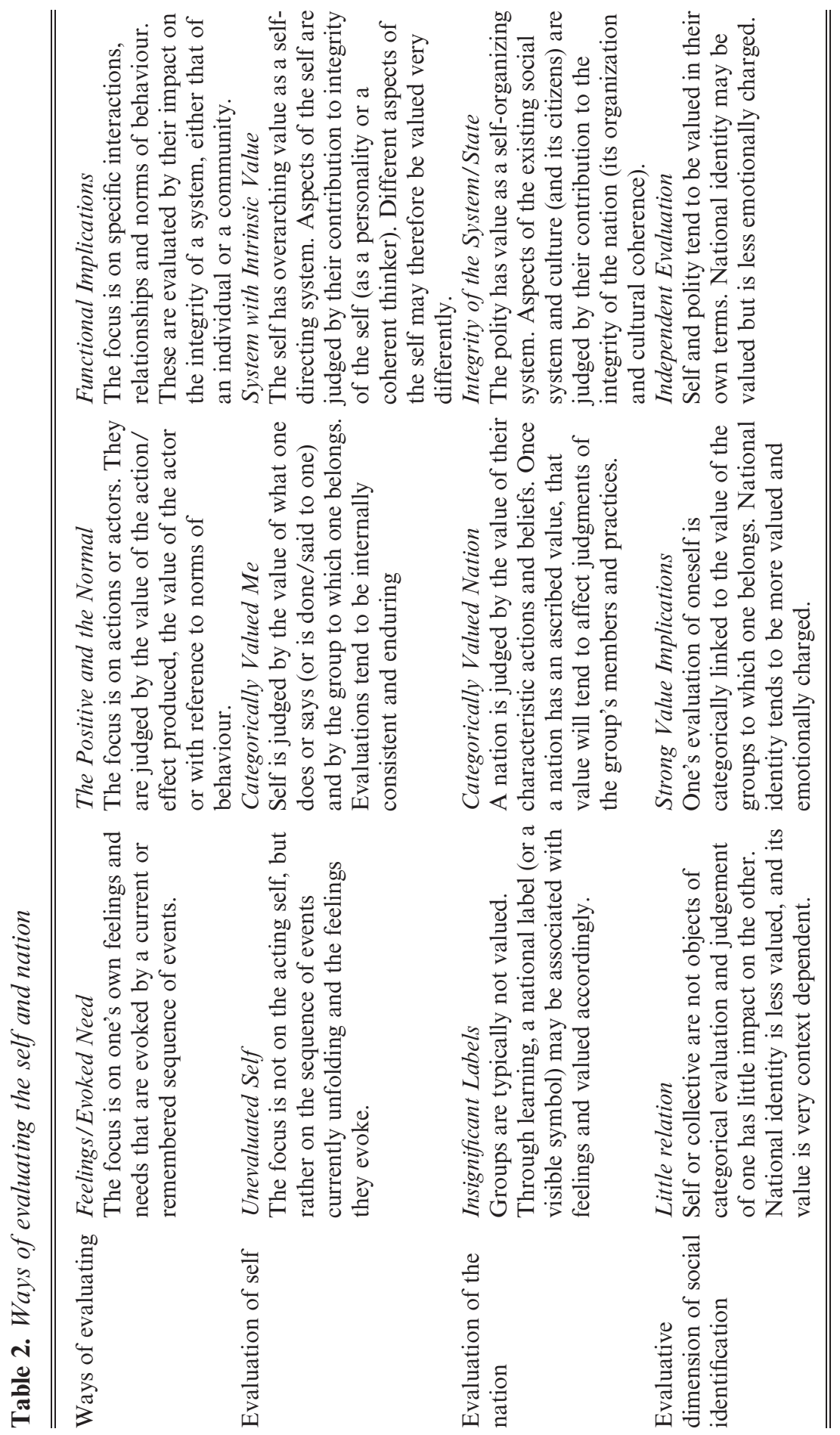

(C) The author(s) 2018. Nations and Nationalism (C) ASEN/John Wiley \& Sons Ltd 2018 
thinking leads to the construction of concrete categories and therefore is likely to define the self, other people and the nation in more categorical terms. Systematic thinking leads to a multi-faceted, integrative conception of objects as self-regulating systems and therefore is less likely to define the self or groups in simple categorical terms.

H2a: Categorical self-identification as American. Linear thinking will produce more. Sequential and systematic thinking will produce less.

$\mathrm{H} 2 \mathrm{~b}$ : Importance that other people identify themselves as American. Linear thinking will yield a greater sense of importance. Sequential and systematic thinking will yield less.

H2c: Perceived homogeneity of Americans. Linear thinking will perceive more homogeneity. Sequential and systematic thinking will perceive less.

3. Impact of different types of thinking on the affective element of national identity: Sequential thinking does not naturally generate an affective attachment to a national identity. The learned value of a national label 'American' will depend on the reinforcement present in the individual's social environment. This makes predictions of affect difficult. Linear thinking produces a categorical concept of the national group and selfidentification and consequently leads to greater affective connection to the nation. It therefore will lead to evaluations that are more positive and patriotism that is 'blind.' Systematic thinking entails more multifaceted judgments and independent valuations of self and the political system. Consequently, it leads to a less affective connection to the nation and therefore to less positive evaluations of the national group and less 'blind' patriotism.

a H4a: Positivity of evaluation. Sequential thinking is difficult to predict. Linear thinking will lead to more positive evaluations, and systematic thinking will lead to less.

b H4b: 'Blind' patriotism. Linear thinking should lead to more. Sequential and systematic thinking should lead to less.

4. Thinking, education and national identity: Type of thinking is related to, but independent of, level of educational attainment. A better measure of cognitive differences, it will be more strongly related to differences in national identification.

a H5a: Although type of thinking and level of education will be related, the relationship will be highly imperfect.

b H5b: Type of thinking will impact national identification independently of and more strongly than level of educational attainment.

\section{Methodology}

The study uses a correlational design to explore the relationship between type of thinking and the logic and affect of national identification. 


\section{Participant population}

A total of 705 individuals solicited online through Amazon's Mechanical Turk participated in the study. Participation was limited to adults (over 18 years of age) who self-identified as American citizens, had at least one parent who was American and logged on to the internet from a computer located in the US. We recognize that the while it is very diverse (and certainly preferable to a student population), Mechanical Turk population is not representative of Americans (Berinsky et al., 2012). We did not regard this to be a problem for the present study. Given the focus on examining the relationship between reasoning and national identity rather than their distribution in the population at large, we needed a diverse sample rather than a representative one.

We were, however, concerned that the diversity of our Mechanical Turk population would be limited in one important way. Mechanical Turk is not likely to include people who have no access to a computer, do not know how to use one or are not sufficiently literate to be able to participate in a study that required extensive reading. In our view, this excludes individuals who are systematically disadvantaged in a variety of ways that are likely to inhibit their cognitive development. Therefore, very few people who typically think in a sequential manner would be included. To address this problem, we actively solicited 45 people at two locations (a shopping mall and a courthouse) in Southern California in geographic areas that, according to US Census data, have a high preponderance of people with high school education or less and low average income levels: populations more likely to have larger proportions of people who think sequentially. These participants typically did require assistance to complete the survey. Working one on one, we helped them to use the computer and assisting them in the reading of questions and response options. We realize this creates some issues of comparability of our two populations, but as in all research there are trade-offs and for our purposes, including participants of this kind was critical.

\section{Method: online survey}

The online survey included several sections. Two presented interactive problem-solving tasks designed to assess the quality of participants' thinking. The remainder included close-ended survey items, most of which replicated questions used in other well-regarded studies of American national identity.

Assessing the quality of reasoning

The quality of participants' thinking was assessed by administering two interactive problem-solving tasks. Both video and written instructions accompanied each task to ensure it was properly understood. The first task, the face sorting task, is a modified version of a classic experimental task designed by L.S. Vygotsky (1962) to assess the respondent's capacity to construct concrete 
categories. In our version, 27 photographs of male faces were presented on the top $2 / 3$ of the screen and a 'wooden' surface for stacking pictures was presented on the bottom 1/3 of the screen. (See Figure 1 below.) The faces were all were divided into thirds by race (white, black and Asian), by age (child, young adult and over 65) and by clothing (bare chested, casual and formal business attire). Participants were instructed to drag the photographs from the top $2 / 3$ of the screen to the bottom and stack the pictures together in a way that 'made sense to them.' After the third photograph was added to the first stack and again after the third photograph was added to the second stack, a pop-up screen appeared asking the participant why they added this third photograph to the stack.

The less demanding task, the face sorting was used to differentiate sequential and linear thinking. Responses were coded as follows:

Sequential thinking focuses on a visually salient attribute of the last photograph in the stack and chooses the next to match. What is visually salient may change when looking at this second photograph after it has been added. For example, the first choice may be a young black formally dressed child. Here, the participant's attention is on the age of the child. So, the participant next adds a photograph of a young white bare-chested child in a swim suit. At this point, it is the bare chest that captures the participant's

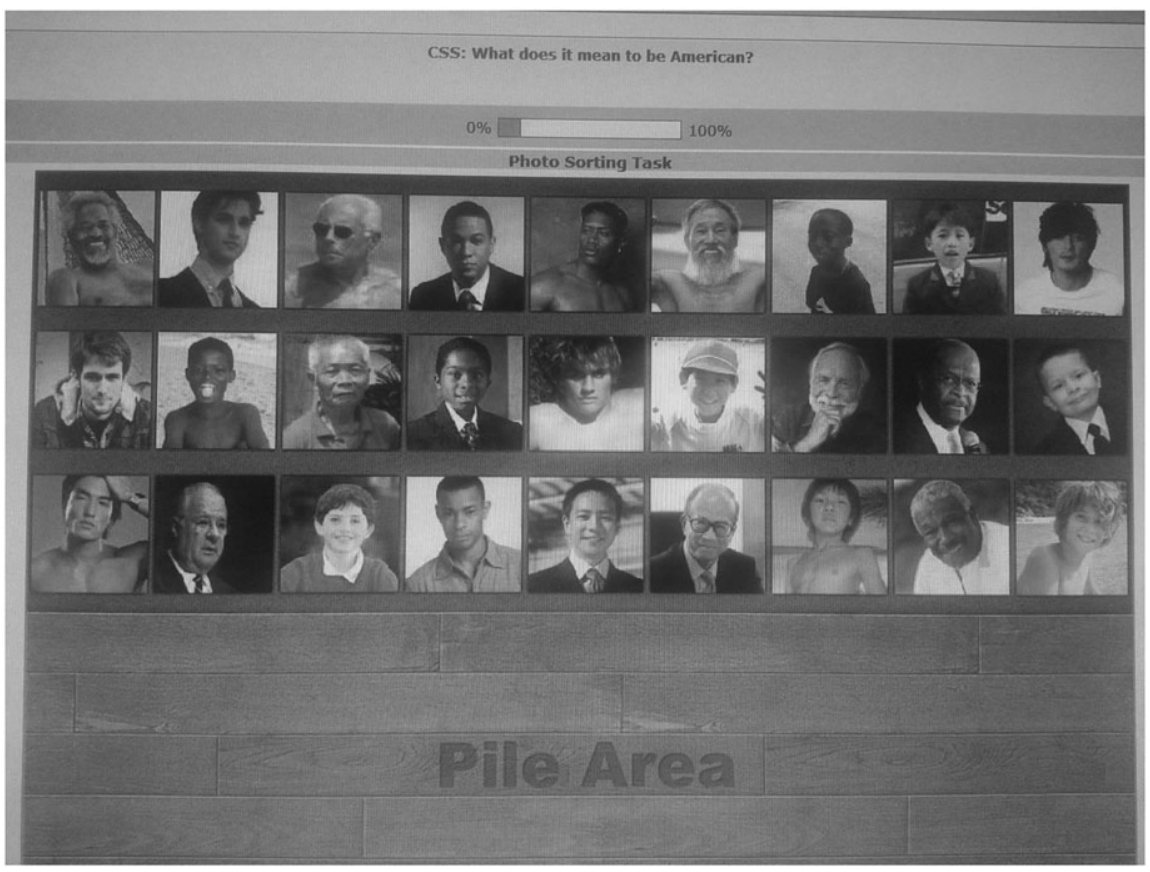

Figure 1. Picture sorting task

(C) The author(s) 2018. Nations and Nationalism (C) ASEN/John Wiley \& Sons Ltd 2018 
attention, and the next photograph chosen may be of an old white bare chested white man. The resulting stack of photographs appears to be a random collection.

Linear thinking involves examining the set of photographs, abstracting one criterion element and then using that attribute to divide the photographs to stacks. For example, the participant may choose to focus on the race of the males photographed. In so doing, the participant may construct the first pile of all black males, the second of all Asian males and the third of all white males. The result is a set of stacks of photographs that look like standard categorical sorts. As this result solves the task adequately, systematic thinking produces the same result.

The more cognitively demanding chemistry task was developed to more effectively differentiate linear and systematic thinking. (It is a modification of a classic and much replicated task designed by Barbel Inhelder and Jean Piaget, 1958). Participants were first presented a training screen that displayed a large empty beaker, an eye dropper and four small flasks (labelled 1-4) filled with colourless liquids. (See Figure 2.) Here participants learned the mechanics of the task, dragging the flask and eye dropper to fill the large beaker and then to push the 'empty button' to allow them to repeat the activity. The next screen presented the first phase of the problem. They were told that pouring the liquid from one or more of the small flasks into the large beaker and then adding the drops would turn the contents of the large beaker the colour yellow. Their task was to discover how to make yellow. The task was designed so that the contents of flasks 1 and 3 combined to make yellow, flask 2 contained a neutralizing agent that prevented the creation of the yellow liquid and flask 4 contained a neutral

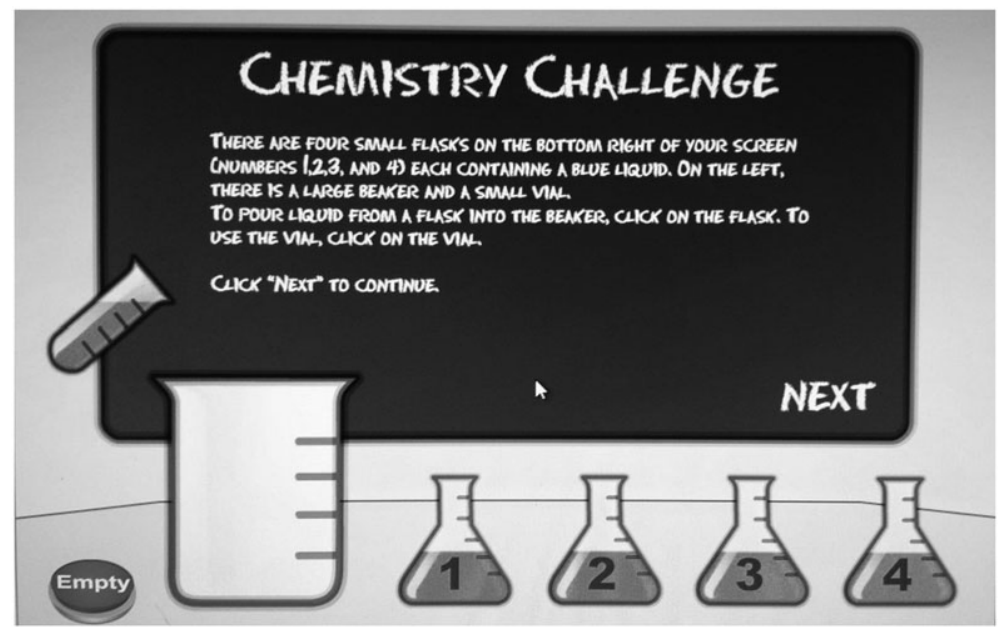

Figure 2. The chemistry task 
agent that had no impact. If participants failed to make yellow and quit the task, they advanced to the next part of the survey. Otherwise, they continued to a new page presenting the second phase of the problem: to figure out what the other liquids (those not involved in making yellow) did. Once the task was completed (or the 'I can't figure it out' button was pushed), participants are asked to describe the role of each flask in making the yellow liquid.

The chemistry task was coded as follows:

Sequential thinking involves observing and learning sequences of events. The task calls for a causal analysis that demands inferences regarding prior steps in a sequence that were never observed. Sequential thinking cannot do this. However, it can follow specific behavioural instructions. The result is random attempts to make the yellow liquid. Typically, this will involve pouring each of the flasks individually and when prompted to try more, several random combinations will be tried. Usually, the participant is unable to make the colour and quits the task.

Linear thinking is linear causal and readily orients to finding prior causes or subsequent effects that have not been observed. A participant thinking in this way typically tries the various beakers individually and in combination in an orderly fashion leading to the discovery that liquids in flasks 1 and 3 combine to produce the yellow liquid. In linear thinking, understanding is achieved when the cause of the observed effect is discovered, and no further inquiry is required. Nonetheless, when prompted, participants engage the second part of the task. Linear thinking involves relating actions (causally or categorically), but it cannot relate relationships. Failing in this regard, it cannot integrate observed relationships to solve the second phase of the task. For example, knowing that flasks 1 and 3 combine to make the yellow liquid and subsequently observing that flasks 1,2 and 3 or all four flasks together do not make the yellow liquid does not lead to the appropriate inferences regarding the effect of flask 2. Instead, it typically leads to the conclusion that the contents of flask 2 'do nothing.'

Systematic thinking involves conceptualizing situations as systems of potentially interrelated parts such that there are potentially multiple causes of a given effect and various different effects that may be produced. Consequently, this leads to addressing the first part of the task in the same manner and with the same success as in linear thinking. However, recognizing that the system of possible interactions has only been partially explored, systematic thinking approaches the second phase of the task assuming there is more to be discovered. Naturally, holding several concrete relationships in mind and relating them to each other, systematic thinking often leads to a strategy of using a known relationship, in this case that flasks 1 and 3 combine to produce a colour, to explore a second, for example 1, 3 and 2, and to deduce how the added element affects the outcome. Consequently, it readily leads to the discovery that flask 2 has a neutralizing effect and flask 4 is neutral. 
Given the unusual nature of their use in this context, some further comment is appropriate on the validity of these two interactive tasks. The issue here is whether performance on the tasks measures, as we suggest, a general cognitive ability or just some aptitude related to the specific tasks themselves. We consider the tasks are valid first because they are based on two standard psychological instruments that were developed specifically for the purpose of studying stages of structural cognitive development. They have been empirically linked to complementary measures of the structure of cognition (e.g. Inhelder and Piaget 1958; Kuhn et al. 1977). In a specifically political context, performance on the original Piagetian chemicals experiment related closely to political reasoning as displayed in open-ended responses in indepth interviews (Rosenberg 1988). Additionally, the research presented here may be considered a further validation of task performance as a measure of general cognitive ability. The evidence suggests that the differences in cognitive capacities assumed to be revealed by performance on the tasks correlate with parallel differences in a very different cognitive task, the construction of a national identity.

Assessing the categorical quality of national identification

Close-ended survey questions were used to assess various dimensions of American national identity. Because of our desire to make clear the relevance of our work on different forms of cognition to existing work on American national identity, most of these questions were drawn from other research on the topic. To assess national identification as a form of self-categorization, we used the four questions posed by Huddy and Khatib (2007) and the more visual instrument presented by Tropp and Wright (2001). The items are:

1. How important is being American to you?

2. To what extent do you see yourself as American?

3. How well does the term American describe you?

4. When talking about Americans, how often do you say 'we' instead of 'they'?

5. Please indicate which pair of circles best represents your level of identification with America or Americans.

We further explore the categorical quality of national identification by asking how important it is that others categorize themselves as American.

1. How important to you is it that other Americans also see themselves as Americans?

2. How important to you is it that other Americans value the fact that they are American?

3. Some people think American people are very similar to each other. Other people say that Americans are very different from one another. What do you think? 
Assessing affect (1): positive bias

Here, we ask a number of questions to assess how motivated participants are to evaluate Americans in a positive light. Participants were presented with pairs of adjectives and asked to rate Americans relative to people from other countries along each dimension.

1. Caring/Cruel

2. Compentent/Incompetent

3. Responsible/Irresponsible

4. Patriotic/Disloyal

5. Generous/Selfish

6. Rational/Irrational

7. Open-minded/Prejudiced

8. Wise/Foolish

9. Honest/Deceptive

10. Harworking/Lazy

Assessing affect (2): 'blind' patriotism

Here, we draw on work on blind patriotism and replicate the questions posed by Schatz et al. (1999). We also add two questions of our own that address issues that have become prominent more recently. Participants were asked how much they agreed/disagreed with the following.

1. People who do not wholeheartedly support America should live somewhere else.

2. I support my country's leaders even if I disagree with their actions.

3. For the most part, people who protest and demonstrate against US policy are good, upstanding, intelligent people.

4. I believe that US policies are almost always the morally correct ones.

5. If I criticize the United States, I do so out of love of country.

6. I oppose some US policies because I care about my country and want to improve it.

7. People should work hard to move this country in a positive direction.

8. The American constitution written by our forefathers is a basically perfect document.

9. All the bickering and arguing among the members of Congress is a bad thing for the country. The US would be better off with just one leader who was a strong, decent, well educated person.

Demographics

Participants were asked questions regarding their age, gender, ethnicity, level of education, income, citizenship and the number of parents born in the US. 


\section{Results}

We analysed the face sorting and chemistry tasks to determine whether we discovered the differences in thinking we expected. Then, we examined whether these differences predicted participants' responses to the various close-ended questions on American national identity.

Differences in types of thinking (H1)

Participants in our study were thinking in the three qualitatively different ways we hypothesized. The tasks were performed in a sequential manner by 34 participants. They sorted the faces in an apparently arbitrary manner and had difficulty discovering or explaining how to combine liquids to make the yellow liquid. Most of the participants (596) performed in a linear manner. They sorted the photographs of faces categorically and succeeded in solving the first part of the chemistry task (discovering that flasks 1 and 3 combined to produce a colour). A total of 120 of the participants performed in a systematic manner. In addition to sorting photographs categorically, they solved the chemistry task fully, making the appropriate inferences regarding the neutralizing and neutral functions of flasks 2 and 4.

Cognitive bases of categorical national identification

Here, we analyse the relation between participants' type of thinking as indicated by their performance on the problem-solving tasks and their response to the survey measures of categorical national identification. To begin, we did a series of one-way analyses of variance of levels of categorical identification by type of thinking. The results of our analysis are presented in Table 3 . Turning first to the degree to which participants self-categorize as Americans, the data support our hypothesis $(\mathrm{H} 2 \mathrm{a})$ that linear thinking leads to more selfcategorization as Americans. This is evident both for the more visual measure

Table 3. ANOVA of type of thinking $\times$ categorical national identification

\begin{tabular}{lcccc}
\hline \hline & $\begin{array}{c}\text { Sequential } \\
\text { thinking }\end{array}$ & $\begin{array}{c}\text { Linear } \\
\text { thinking }\end{array}$ & $\begin{array}{c}\text { Systematic } \\
\text { thinking }\end{array}$ & $p=$ \\
\hline $\begin{array}{l}\text { Predicted degree of } \\
\text { categorization }\end{array}$ & Less & More & Less & \\
$\begin{array}{l}\text { Categorical self-identification } \\
\quad \text { Venn diagram (1 item) }\end{array}$ & 4.38 & 5.11 & 4.68 & .006 \\
$\quad$ Self Cat items +Venn diagram & 3.70 & 3.91 & 3.64 & .002 \\
$\begin{array}{l}\text { Categorical other-identification } \\
\quad \text { Others identify as American }\end{array}$ & 2.76 & 2.90 & 2.57 & .001 \\
$\quad \begin{array}{l}\text { Americans similar to one } \\
\text { another }\end{array}$ & 2.65 & 2.96 & 2.63 & .028 \\
\begin{tabular}{l} 
Number of Participants \\
\hline \hline
\end{tabular} & 34 & 596 & 120 & \\
\hline
\end{tabular}


of self-categorization (the overlapping Venn Diagrams of 'self' and 'Americans') and the verbal four-item scale. There is also evidence that different types of thinking affect the degree to which other Americans are conceived in categorical terms. As hypothesized, linear thinking is more likely than either sequential or systematic thinking to lead to the views that other Americans should categorize themselves as American $(\mathrm{H} 2 \mathrm{~b})$ and that Americans are a relatively homogeneous group $(\mathrm{H} 2 \mathrm{c})$.

Affective quality of national identification

The results for the analysis of the relationship between type of thinking and the evaluative and affective dimensions of participants' national identity are presented in Table 4. Here, we hypothesized that linear thinking would generate a greater favourability bias toward Americans and a more affectively loaded, more 'blind' patriotism compared to systematic thinking. We also expected sequential thinking to generate less evaluative bias and affective attachment to nation, but because of the vagaries of learning in specific social contexts, we were less confident in our predictions. The results for systematic and linear thinking are strong and clear in the directions predicted. Compared to systematic thinking, linear thinking generates a more positive evaluation of Americans and higher levels of patriotism. However, the results for sequential thinking indicated that evaluations of Americans and patriotism were very similar for those of linear thinking.

Education vs. type of thinking

Our analysis of the relationship between level of educational attainment and the development of type of thinking (from sequential to linear to systematic) unsurprisingly indicates the two are positively correlated $(.17, p<.01)$. As one progresses through school to college and post-graduate education, one is more likely to think in a more abstract, integrative and principled way. Presumably this reflects the impact of education on cognition, although the direction of causation may be the reverse. However, for our present purpose, the key finding is how imperfect the relationship is (only 3 per cent of the variance explained). This implies that type of thinking is importantly independent of

Table 4. ANOVA of type of thinking $\times$ affective quality of national identification

\begin{tabular}{lcccc}
\hline \hline & $\begin{array}{c}\text { Sequential } \\
\text { thinking }\end{array}$ & $\begin{array}{c}\text { Linear } \\
\text { thinking }\end{array}$ & $\begin{array}{c}\text { Systematic } \\
\text { thinking }\end{array}$ & $p=$ \\
\hline $\begin{array}{l}\text { Predicted affective/evaluative } \\
\text { strength }\end{array}$ & Less? & More & Less & \\
$\begin{array}{l}\text { Favourability bias in evaluating } \\
\text { Americans }\end{array}$ & 4.19 & 4.14 & 3.93 & .000 \\
\begin{tabular}{l} 
Level of blind patriotism \\
\hline \hline
\end{tabular} & 3.55 & 3.21 & 2.81 & .000 \\
\hline
\end{tabular}

(C) The author(s) 2018. Nations and Nationalism (C) ASEN/John Wiley \& Sons Ltd 2018 
level of educational attainment and the latter cannot be used as a surrogate for the former.

In this light, we examined the relative effect of type of thinking and level of education on the formal quality, substantive content and the affective dimension of American national identification. We conducted a two-way analysis of variance to examine the effects of type of thinking and level of education on national identification. The results are presented in Table 5. Looking first at the categorical quality of national identification, we find main effects of type of thinking for both the visual (Venn diagram) and verbal item measures of self-categorization. There is no significant main effect for level of education. Turning to the ascribed importance of identifying categorically as American, there is a significant $(P<.01)$ main effect for type of thinking on selfidentification and near significant effect $(p<.10)$ on others identifying as American. However, there is no effect of type of thinking on the last indicator, the perceived homogeneity of Americans. There is no significant main effect of level of education on any of the measures of the categorical quality of national identification. In sum, there is strong evidence that, when viewed together, type of thinking has strong effects on the categorical quality of national identification whereas level of education does not.

Turning to the effect of level of educational attainment and type of thinking on the more affectively loaded aspect of national identification, the results are more mixed. Although the overall model was significant, neither education nor type of thinking had an independent main effect on the favourability of

Table 5. Effect of type of thinking and level of education on American national identification (summary of F-scores for two-way analysis of variance)

\begin{tabular}{|c|c|c|c|c|}
\hline & $\begin{array}{c}\text { Corrected } \\
\text { model }\end{array}$ & $\begin{array}{c}\text { Main effect } \\
\text { of type of } \\
\text { thinking }\end{array}$ & $\begin{array}{c}\text { Main effect } \\
\text { of level of } \\
\text { education }\end{array}$ & $\begin{array}{c}\text { Interaction } \\
\text { effect }\end{array}$ \\
\hline \multicolumn{5}{|l|}{ Categorical self-identification } \\
\hline Venn diagram (I item) & $3.008 * *$ & $5.309 * *$ & 2.144 & 1.647 \\
\hline Self-categorization (4 item) & $3.565^{* *}$ & $5.265 * *$ & 2.841 & 2.217 \\
\hline \multicolumn{5}{|l|}{ Import of national identification } \\
\hline For one's self & $3.241 * *$ & $4.744 * *$ & .525 & .076 \\
\hline Others identify as American & $2.62 * *$ & $5.309 * *$ & 2.76 & .449 \\
\hline \multicolumn{5}{|l|}{ Homogeneity of category } \\
\hline Americans are the same & 1.383 & 2.082 & .647 & .689 \\
\hline \multicolumn{5}{|l|}{ Evaluation of Americans } \\
\hline Favourability & $2.083^{*}$ & 1.213 & 4.080 & .680 \\
\hline Level of blind patriotism & $7.111 * * *$ & $3.860^{*}$ & $10.333 * * *$ & $3.557^{*}$ \\
\hline
\end{tabular}


people's judgments of Americans. In the case of blind patriotism, there is evidence of significant main effects of both type of thinking and level of education as well as an interaction effect. However, here the effect of education was stronger than that of type of thinking.

In sum, the evidence suggests that although level of education and type of thinking are correlated, the former is a very imperfect indicator of the latter. More important, the evidence clearly indicates that when the two factors are analysed together, the effect of type of thinking on the different aspects of national identification is independent of and stronger than those of level of educational attainment.

\section{Conclusion}

Most research on national identity assumes that all people have a similar, categorical way of understanding themselves and their nationality. Returning to fundamental questions regarding the quality of cognitive processing and the understanding it generates, we argued that not all people think in the same categorical manner suggested. Building on Rosenberg's typology (Rosenberg 2002), we described three qualitatively different ways - sequential, linear and systematic - that people think about themselves, the nation and their relationship to it. We hypothesized that these differences would be evident in participants' performance on online interactive problem-solving tasks and in their response to traditional survey items used to measure self-categorization as American and the affective aspect of national self-identification. Overall, the results provide strong support for the hypotheses. Additionally, there is clear evidence that these differences in the cognitive bases of national identification cannot be reduced to level of education.

Consistent with most studies of social and national identity, our research suggests that most people think in the concrete, simple categorical and linear causal terms typical of linear thinking. In the photograph sorting task, the majority of our participants readily focused on a single feature (e.g. people's age), abstracted it from the visual context of the photographs, held that feature in mind and then sorted the photographs accordingly. When asked to discover the cause of a chemical reaction, these participants held the effect in mind and tested for possible causes in order to discover the particular combination that produced the observed reaction. They also responded to the questions typically asked in studies of American national identity along the lines observed in that research. They tended to self-categorize as American and believe that other Americans should do so as well. Moreover, they saw the category of American as relatively homogeneous and felt a sense of shared fate with their fellow nationals. They evidenced a tendency to judge Americans relatively favourably and to value being American. They also expressed relatively high levels of blind patriotism. 
However, our research also indicates that many people did not think in a linear categorical way and therefore did not identify with the nation in the ways typically described. A significant portion of our participants responded to the problem-solving tasks and the national identity questions in a more cognitively developed, systematic way. Conceptualizing the chemistry task as involving a system of possible interactions, they explored the various relationships among the liquids relative to one another and were therefore able to deduce the role of the neutral and neutralizing agents. Thinking in terms of systems rather than simple categories, these participants were less inclined to self-categorize themselves as Americans and thought it less important that others do so as well. They were also less likely to see Americans as a homogeneous group. They also evidenced less affective attachment to the nation. They were less favourable when evaluating Americans and were less blindly patriotic. Overall compared to linear thinking, systematic thinking fostered a form of national identification that was less like what has usually been observed in empirical research and more like the ideal citizen postulated in democratic theory.

Perhaps most surprising are the participants whose thinking was sequential. Thinking in terms of event sequences rather than categories or linear causes, they did not construct coherent, categorical stacks of photos in the face sorting task. They also did not discover how to produce the coloured liquid in the chemicals task. As hypothesized, they were less likely to self-categorize as American, to see the need for others to do so or view Americans as similar to one another. The effect of sequential thinking on the affective dimension of national identification was more mixed. As predicted, it was related to less common feeling with the nation. Contrary to our expectations, sequential thinking generated the same level of favourable evaluation of Americans and even higher levels of blind patriotism. One possible explanation is that sequential thinking leads to less gradation in evaluation thus producing relatively extreme responses even when affective and emotional commitments are not particularly strong. However, this remains a matter for future research on this less accessible and therefore more understudied segment of the population.

One question that may be raised here is does, as we suggest, variation in the performance of the cognitive tasks reflect discrete, structurally different forms of thinking or does it reveal differences in degree of intelligence. Both theoretical considerations and the empirical results suggest the variation is better understood from our structural developmental perspective. Our typology led to clear inferences regarding the different ways in which people would conceptualize themselves, the nation and their relationship to it. Adopting a more linear view of intelligence (e.g. as reflected in IQ measures), it is not at all clear how one could theoretically deduce the relationship between degree of intelligence on the one hand and variation in self-categorization as American, the importance of being American or patriotism on the other. Turning to the empirical evidence, it is also not evident how this linear view of intelligence would explain our curvilinear results that indicate relatively low levels of national identification among highest as well as the lowest performing of our respondents. 
There are a number of implications of the research reported. First, the empirical research on national identity should attend to individual differences in cognition. Most research to date has assumed that people all think in the same, categorical way. Hypotheses are generated, and research is designed accordingly. The hypotheses are generally confirmed, but in our view this is because the majority of people studied think in what we would term this linear fashion. Although there are significant numbers of participants who think in a nonlinear fashion, given the design of this research, their responses only surface in the data analysis as random or experimental error. Our work, however, demonstrates that the responses of sequential and systematic thinkers in fact deviate from those of linear, categorical thinkers in predictable, non-random ways.

This suggests that future research should utilize methods that are sensitive to cognitive differences. Not only would this entail using measures of types of cognitions such as those employed here, but it would also involve constructing measurement instruments that are sensitive to the possibly different ways in which people may understand the same stimulus items. For example, people thinking sequentially might readily agree with statements that being American is important and that being a 'true' American requires voting and obeying the law. But in an interview, they are also likely to state that they do whatever they want - they never really bother to vote and they believe that it is okay to break the law, especially when you are not caught. This kind of response, incomprehensible in the terms of linear or systematic thought, is typical of sequential thinking. Whether it involves the use of in-depth interviews, survey instruments or experiments, research must be designed in a way that is sensitive to these kinds of differences.

Future research should also address new substantive questions. To begin, it should go beyond our research and its limited participant population to identify the prevalence of different types of thinking in the population at large. Drawing on census reports of illiteracy and extrapolating from studies of small populations, some researchers have speculated that about 20 per cent of Americans think sequentially, 65 per cent think linearly and 15 per cent think systematically (e.g. Rosenberg 2002). While intriguing, speculation is here is not enough and research with representative populations is needed in the US and other countries.

Beyond establishing the prevalence of different cognitively structured forms of national identification, research should also explore the varying causes and effects of nationalism for different types of thinking. For example, with regard to causes, it is likely that expressions of nationalism by people who are thinking sequentially are most affected by the availability of relevant rewards in the immediate environment, such as those provided by people around them actively encouraging the expression of nationalist sentiment. Alternatively, it is likely that the nationalism of people who are thinking systematically will be most affected when the nation is perceived to act in a way that conforms to or violates their basic moral or political principles. More generally, there is a need to investigate the efficacy of different ways of mobilizing citizens who think in structurally different ways. Turning to the effects of different ways of constructing one's 
relation to the nation, it is likely that sequential thinkers have the most unreliable attitudes to the nation and are most fickle in their loyalties. Alternatively, those people who think systematically are most likely to demonstrate a patriotic fervour for the basic principles of association which define their society. Eschewing the more ethno-nationalism of their linear counterparts, theirs would be what Habermas (1994) terms a more 'constitutional patriotism.'

Finally, there are important questions regarding the conditions which promote or inhibit the development of thinking and the associated forms of national identification. Developmental theory suggests that structural change is fostered when (1) people's pragmatic understandings are undermined, that is when their expectations regarding what is routine and regular in everyday life are disrupted, and (2) they are provided some intellectual 'scaffolding' upon which they can draw to construct new types of understandings. These general claims raise a myriad of questions that are best explored experimentally regarding the specifics of how this is accomplished in different ways for different types of thinking. Special attention should be paid here to the particular role that politically relevant understandings may play in this process.

These developmental considerations lead to a final, expressly political implication of our work. Our findings raise serious concerns about the contemporary politics of the flagship democracies of Europe and North America. If most citizens of these democracies think in linear terms, they cannot be expected to adequately understand or value the abstract concept of citizenship or principles of social integration and governance that these now multicultural polities require. Instead of being 'constitutional patriots', they will more naturally think in ethno-nationalist terms. As such they will be always be vulnerable to the exclusionary and essentially racist rhetoric of the kind now voiced by many rightist and populist parties. On the face of it, our research thus seems to support the claims of a Samuel Huntington over those of a Jurgen Habermas. However, this is to ignore the developmental theory driving our research. It suggests that development of systematic thinking is within the grasp of most people. As such, it is the responsibility of society to better understand and create the conditions - educational, economic and cultural - that facilitate development. Put in more political terms, the first responsibility of a democracy is to create the citizenry it requires.

\section{References}

Berinsky, A. J., Huber, G. A. and Lenz, G. S. 2012. 'Evaluating online labor markets for experimental research: Amazon.com's Mechanical Turk', Political Analysis 20: 351-368.

Citrin, J. and Sears, D. O. 2014. American Identity and the Politics of Multiculturalism. New York: Cambridge University Press.

Citrin, J., Wong, C. and Duff, B. 2001. 'The meaning of American national identity' in R. D. Ashmore, L. Jussim, D. Wilder (eds.), Social Identity, Intergroup Conflict and Conflict Resolution. New York: Oxford University Press: 71-100. 
De Figueiredo, R. and Elkins, Z. 2003. 'Are patriots bigots? An inquiry into the vices of in-group pride', American Journal of Political Science 47, 1: 171-118.

Festinger, L. 1957. A Theory of Cognitive Dissonance. Stanford: Stanford University Press.

Habermas, J. 1981/4. The Theory of Communicative Action. Vols. 1 \& 2. Boston: Beacon Press.

Habermas, J. 1994. Struggles for Recognition in the Democratic Constitutional State. Princeton, NJ: Princeton University Press.

Heider, F. 1958. The Psychology of Interpersonal Relations. Hillsdale NJ: Erlbaum.

Hogg, M. A. and Abrams, D. 1988. Social Identifications: A Social Psychology of Intergroup Relations. New York: Routledge.

Huddy, L. and Khatib, N. 2007. 'American patriotism, national identity and political involvement', American Journal of Political Science 51, 1: 63-77.

Inhelder, B. and Piaget, J. 1958. The Growth of Logical Thinking from Childhood to Adolescence. New York: Basic Books.

Kegan, R. 1994. In over our heads. Cambridge, MA: Harvard University Press.

Kohlberg, L. 1981. Essays on moral development: The philosophy of moral development. (Vol. 1). San Francisco: Haper \& Row.

Kosterman, R. and Feshback, S. 1989. 'Toward a measure of patriotic and nationalistic attitudes', Political Psychology 10, 2: 257-274.

Kuhn, D. et al. 1977. 'The development of formal operations in logical and moral judgments', Genetic Psychology Monographs 95: 97-188.

Rosenberg, S. W. 1988. 'The structure of political thinking', American Journal of Political Science 32, 3: 539-566.

Rosenberg, S. W. 2002. The Not So Common Sense: Differences in How People Judge Social and Political Life. New Haven: Yale University Press.

Schatz, R. T., Staub, E. and Lavine, H. 1999. 'On the varieties of national attachment: blind vs constructive patriotism', Political Psychology 20, 1: 151-174.

Schildkraut, D. J. 2014. 'Boundaries of American identity: evolving understanding of 'US', Annual Review of Political Science 17: 441-460.

Schwartz, S. J. et al. 2012. 'The American identity measure: development and validation across ethnic group and immigrant generation', Identity 12, 2: 93-128.

Sniderman, P. M., Hagendoorn, L. and Prior, M. 2004. 'Predisposing factors and situational triggers: exclusionary reactions to immigrant minorities', American Political Science Review 98, 1: 35-49.

Tajfel, H. 1981. Human Groups and Social Categories. Cambridge: Cambridge University Press.

Tropp, L. R. and Wright, S. C. 2001. 'Ingroup identification as the inclusion of ingroup in the self', Personality and Social Psychology Bulletin 27: 585-600.

Turner, J. C. et al. 1994. 'Self and collective: cognition and social context', Personality and Social Psychology Bulletin 20: 454-463.

Vygotsky, L. S. 1962. Thought and Language. Cambridge: MIT Press. 